\title{
Attention Deficit Hyperactivity Disorder Detection - from Psychological Checklists to Mobile Solutions
}

\author{
Kamil Żyła ${ }^{1}$ \\ ${ }^{1}$ Department of Computer Science, Lublin University of Technology, Poland
}

\begin{abstract}
The notion of Attention Deficit Hyperactivity Disorder (ADHD) may have its origins in 1763, when Scottish physician Sir Arthur Crichton observed people who could be easily distracted to a degree approaching the nature of delirium. Since then, the notion of ADHD matured and aroused controversy concerning whether it is a real illness and the motives behind particular methods of its treatments. Despite the controversy, ADHD is well established as a research subject and a frequently diagnosed disorder. Thus, the aim of this paper is not to deal with controversies but rather to show the evolution of methods used for the detection of this disorder. Literature analysis revealed that those methods varied from classical psychological tests/questionnaires to analyses of: eye-motion, micro-motion, brain activity, and behavioral patterns in virtual reality. The main conclusion is that the above methods tend to be heavily computer-aided and that the future belongs to mobile solutions incorporated into complex e-health systems.
\end{abstract}

\section{Introduction}

Due to the fast pace of life as well as the technological and organizational progress of modern societies, new opportunities for computer-aided methods in mental health sciences arise. Facing such opportunities should result not only in policy making and analysis, but also in supporting researchers, medical doctors, patients, and their families with very accurate data acquisition devices and methods, as well as advanced algorithms for patients' data storage and analysis (Henson et al., 2019). Even social reporting systems could take part in this ecosystem, providing data about patient's behavior in his/her natural environment, including situations of being surrounded by other people during everyday activities.

Nowadays, access to the mobile Internet is quite common and cheap. Forrester (Taylor, 2015) predicted that by the end of 2016, 4.8 billion people globally would use a mobile phone, while $46 \%$ of the population would 


\section{Kamil Żyła}

use a smartphone. According to Gartner, the global sales of smartphones to end users in the second quarter of 2019 totaled 368 million units (Goasduff, 2019). The growth of the mobile medical apps market is very dynamic as well. Figure 1 presents a forecast distribution of the mobile medical apps market value in 2017 - a percentage breakdown of EUR 17.6 billion (European Commission, 2018). By 2020, this value could be as much as $35 \%$ higher (Orbis Research, 2017). The global mobile medical apps market alone is predicted to grow from $\$ 1.40$ billion in 2016 to $\$ 11.22$ billion by 2025 (BIS Research, 2018). Finally, although accompanied with certain barriers, introducing high technology in healthcare is recognized to have noticeable advantages (Kristensen et al., 2006; Namahoot \& Brückner, 2015; Pędziński et al., 2013; Ziniewicz et al., 2011). The aforementioned technological progress also has an impact on Attention Deficit Hyperactivity Disorder (ADHD) diagnosis, monitoring, and treatment.

The concept of ADHD emerged in its full form in the late 1950s in USA and then spread globally. Smith (2017) claims that the global rate of the disorder is 5.29\%. According to the 5th edition of the American Psychiatric Association's Diagnostic and Statistical Manual of Mental Disorders (DSM), ADHD can be diagnosed as one of 3 types: inattentive, hyperactive/impulsive, or combined (APA, 2013). In the case of the inattentive type, six (or five for people over 17 years) of the following symptoms have occurred frequently over the past 6 months (cited from (APA, 2013; APA, 2017)):

- does not pay close attention to details or makes careless mistakes in school or job tasks,

- has problems staying focused on tasks or activities, such as during lectures, conversations or long reading,

- does not seem to listen when spoken to (i.e. seems to be elsewhere),

- does not follow through on instructions and does not complete schoolwork, chores or job duties (may start tasks but quickly loses focus),

- has problems organizing tasks and work (for instance, does not manage time well; has messy, disorganized work; misses deadlines),

- avoids or dislikes tasks that require sustained mental effort, such as preparing reports and completing forms,

- often loses things needed for tasks or daily life, such as school papers, books, keys, wallet, cell phone and eyeglasses,

- is easily distracted,

- forgets daily tasks, such as doing chores and running errands; older teens and adults may forget to return phone calls, pay bills and keep appointments. 


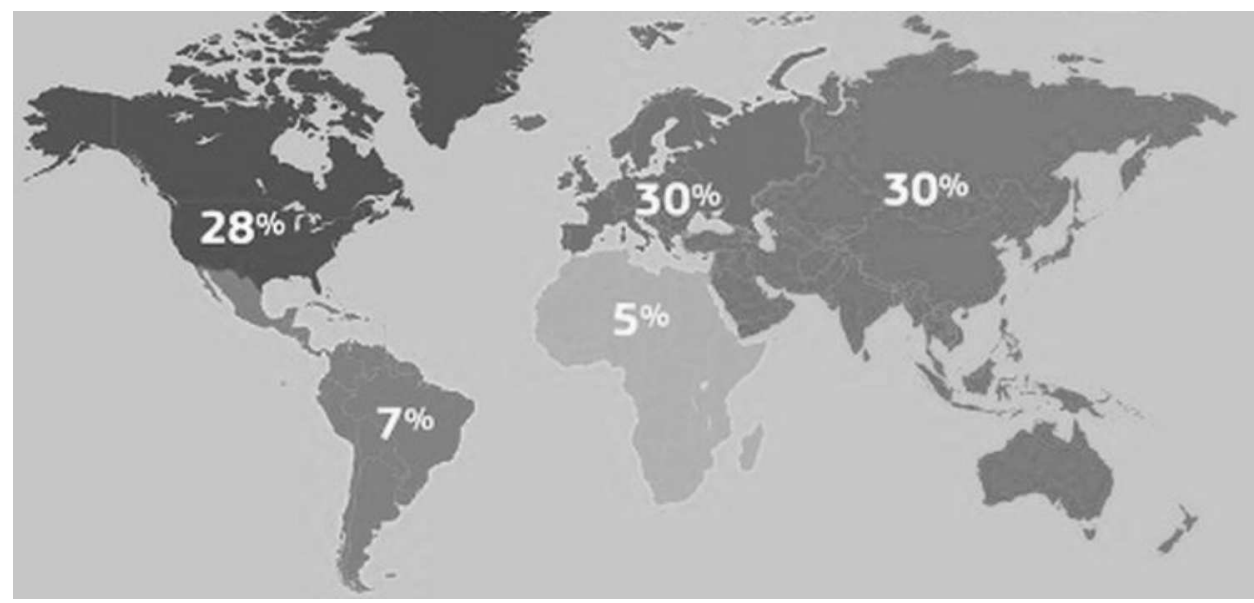

Figure 1. Percentage distribution of the mobile medical apps market value in 2017 (European Commission, 2018)

In the case of the hyperactive/impulsive type, six (or five for people over 17 years) of the following symptoms occur frequently (cited from (APA, 2013; APA, 2017)):

- fidgets with or taps hands or feet, or squirms in seat,

- not able to stay seated (in classroom, workplace),

- runs about or climbs where it is inappropriate,

- unable to play or do leisure activities quietly,

- always "on the go," as if driven by a motor,

- talks too much,

- blurts out an answer before a question has been finished (for instance may finish people's sentences, can't wait to speak in conversations),

- has difficulty waiting his or her turn, such as while waiting in line,

- interrupts or intrudes on others (for instance, cuts into conversations, games or activities, or starts using other people's things without permission); older teens and adults may take over what others are doing.

The aforementioned symptoms were explicitly cited (as is) after the American Psychiatric Association without taking into account their correctness or justification. The reason is to provide an overview of the disorder, without delving into too much details. Nevertheless, the author acknowledges that there is an ongoing discussion concerning the presented definition. Some of the critical voices can be found in (Epstein \& Loren, 2013; Smith, 2017; Steinau, 2013). Other disagreements concern the treatment of the disorder (Smith, 2017) and whether the disorder even exists at all 


\section{Kamil Żyła}

(Saul, 2014). In line with the purpose of this paper, the author will not delve into these problems as well.

According to APA (2017), no laboratory test to diagnose ADHD exists and diagnosis involves collecting information from parents, teachers and other people the examined person has contact with, and filling out checklists. This is followed by a medical examination, including vision and hearing screening, to rule out medical issues other than ADHD.

Classically, in order to aid the process of diagnosis, CPTs Continuous Performance Tests/Tasks) are frequently used. Among the variety of tests, it is worth to point out the following: Integrated Visual and Auditory CPT (IVA-2) (Tinius, 2003), Test of Variables of Attention (T.O.V.A.) (Rotem et al., 2019) and the Conners' CPT-III (Conners, 2014). CPTs assist health professionals assessing three core symptoms of ADHD - hyperactivity, inattention, and impulsivity.

Nevertheless, there is still much space for engineers to develop new solutions helping in ADHD diagnosis or aid those mentioned above. Thus, the following chapters are discussing the trends in research and technology that contribute to ADHD detection through computer and mobile device support. This topic is still relevant, as the global rate of the disorder is $5.29 \%$ (Smith, 2017) and important, as untreated ADHD leads to a significantly decreased quality of life as well as a higher risk of unintentional injuries.

\section{Study Aim and Methods}

The purpose of this paper is to present trends in research concerning computer-aided methods of ADHD detection. The complementary purpose is to indicate areas where applying modern knowledge and technology is particularly useful and to establish the role of mobile technologies in the context of ADHD detection. An analysis of the controversies surrounding the ADHD definition and treatment methods (despite them being acknowledged by the author) is beyond the scope of this paper.

In order to achieve the aforementioned aims, literature analysis was performed. It involved the following bibliographical databases: Springer Link, IEEE Explore, Science Direct, Google Scholar, Scopus, Web of Science. First the "ADHD detection methods" query was run. The returned research papers were grouped according to ADHD detection method, keeping in mind the diversity of disorder indicators as well as the criterion of the method being technology/computer-aided. Then, queries specifying the particular methods were run in the bibliographical databases mentioned above. In or- 
der to fill in possible gaps, references from chosen papers were also analyzed. Each time the language was limited to English. No limit on publication date was imposed in any of the queries. Finally, the papers representative for each ADHD detection method were chosen to be presented in this paper.

\section{Trends in Computer-aided Methods of ADHD Detection}

Different paths are chosen when it comes to technology and ADHD indicators involved in the disorder prediction process. Based on the literature query, the following can be indicated: micro-motion analysis, brain activity analysis, eye-motion analysis, analysis of human behavior in virtual reality, and finally, computer-aided analysis of questionnaires.

Micro-motions analysis. The main idea behind micro-motion analysis is registering movements of the examined person while he/she is performing a specially designed computer test. The test usually lasts no more than half an hour and by design it should be entertaining for the participating person. At the same time, the person's behavior is registered by highly precise motion tracking devices. Then, patterns of motion, accuracy of responses, and fluctuations in attention state are subjected to computer analysis. Its results provide valuable information on the existence and size of ADHD-related deficits compared to results expected for typically developing individuals of the same age and gender. The results also provide information about the probability and relative severity of the disorder in the context of the unique profile of the examined person. (Pearson, 2019)

An example of a tool that uses micro-motion analysis is the Quotient ADHD System, based on the McLean Hospital and Harvard Medical School Affiliate studies. It provides measures of hyperactivity, impulsivity, and inattention that are useful in the clinical assessment of ADHD. The tool reports shifts in aforementioned measures as well, in order to engage patients and guardians in the treatment planning process. (Cloud, 2011; Pearson, 2019)

Brain activity analysis. The occurrence of ADHD symptoms is related to anatomical and biochemical disorders of the frontal lobe (Monastra \& Lubar, 2000), which has been confirmed by studies using EEG (Electroencephalography) (Bresnahan \& Barry, 2002; Markovska-Simoska \& PopJordanova, 2011; Monastra \& Lubar, 2000; Ogrim et al., 2012), MRI (magnetic resonance imaging) (Monastra \& Lubar, 2000; Paloyelis et al., 2007), 


\section{Kamil Żyła}

PET (positron emission tomography) (Monastra \& Lubar, 2000; Weyandt et al., 2013) and SPECT (single photon emission computed tomography) (Monastra \& Lubar, 2000; Schneider et al., 2014). The accuracy of diagnosis based on QEEG (Quantitative EEG), according to Monastra \& Lubar (2000) and Ogrim et al. (2012), can reach 85\%-95\%, although according to Ogrim et al. (2012), opinions are divided on this issue.

Diagnosis of ADHD using QEEG is based on a non-invasive study of bioelectrical brain activity using an electroencephalograph. During the examination, electrodes are placed on the surface of the skull's skin. Their task is to register changes in electrical potential arising as a result of neuronal activity in the brain.

Attempts have been made to combine QEEG with the IVA + CPT (Integrated Visual and Auditory Continuous Performance Test) (Hall et al., 2015; Kim et al., 2015; La Marca et al., 2018). The person taking part in the test is ordered to focus on both visual and auditory stimuli. The test also checks the divisibility of attention, associated with the functioning of the frontal lobe of the brain.

Eye-motions analysis. There is a relationship between eye-motion parameters and ADHD. Acquisition of these parameters with the use of an eye-tracker is gaining popularity, although it can be stated that it is still in the experimental phase. (Fried et al., 2014; Puig et al., 2013; Rojas-Líbano et al., 2019)

One of the methods involves the acquisition of parameters related to micro-saccades, pupil movements, and the number of blinks when performing a CPT test. The test's authors note that untreated people with ADHD have problems controlling blinking in both eyes and show a characteristic pattern of micro-saccades, which, due to their involuntary nature, are the most promising marker of this disorder. (Fried et al., 2014)

The second method is based on the relationship between eye convergence and focusing of visual-spatial attention in adults. Convergence is the simultaneous movement of eyeballs towards the anterior median line due to the contraction of medial straight muscles of the eyes. Studies have shown that during eye fixation (in ophthalmology - the phenomenon of directing the central parts of the retinas (yellow spots) of both eyes at the object being viewed), visual stimuli modulate the angle of eye vergence (AoEV) depending on the ability to focus attention. (Puig et al., 2013)

Analysis of human behavior in virtual reality. Modern technological achievements in the field of Virtual Reality (VR) are conducive to 
innovation in the field of neuropsychological assessment of cognitive processes. The task of VR is to create a three-dimensional environment with which the examined person can interact in a way similar to the real world. The tool, i.e. virtual reality, can successfully perform a supportive function in research using EEG, eye-trackers, or other equipment recording the parameters/behavior of the examined person.

An example of using VR in diagnostics is AULA, i.e. the CPT test transferred into virtual reality and visualized with the use of VR glasses with motion sensors. AULA gives the opportunity to study response to visual-auditory stimuli when introducing distractors. The location of the examined person in a three-dimensional environment makes the examination process more realistic, through a more natural simulation of conditions and environment conducive to the occurrence of attention disorders and ADHD (Díaz-Orueta et al., 2014).

The use of VR as an environment in which diagnostics is carried out has also been described by other authors, to mention (Adams et al., 2009; Nolin et al., 2016; Parsons et al., 2007; Pollak et al., 2009; Rizzo et al., 2004; Ryan, 2017; Yeh et al., 2012). The results of these research studies allow to conclude that the potential of virtual reality can at least be used to support the diagnosis of attention disorders. What is more, actions have been taken to use the virtual environment as a part of therapy (Rohani et al., 2014; VRMC, 2019).

Computer-aided analysis of questionnaires. Questionnaires (i.e. sets of questions addressed to teachers, parents, etc.) regarding the behavior of diagnosed persons during their daily activities (e.g. at work or school) still play an important role in diagnosing ADHD. In such cases, the main task of computer systems is to analyze the collected data and manage the diagnosis and treatment process. An important aspect is also communication between these systems to obtain, provide, or exchange data.

"mehealth for ADHD" is an example of the computer systems mentioned above. According to its assumptions, the diagnosis of a person is two-stage. The first stage is issuing a preliminary diagnosis based on observations during a computer game. The next stage is verification of the initial diagnosis on the basis of questionnaires filled in during observation of the examined person in his/her natural environment. The second stage is used to determine whether ADHD or another disorder is actually present, as well as to determine how the patient responds to treatment, i.e. whether the prescribed treatment alleviates the symptoms of the disorder. (Gruessner, 2015) 
"mehealth for ADHD" belongs, according to Gruessner (2015), to the category of "remote monitoring tools" and may contribute to the improvement of the quality of medical services. The system helps in (Optimal Medicine, 2019a; Optimal Medicine, 2019b):

- acquisition of data on symptoms and the course of treatment (e.g. the system sends questionnaires, reminds about completing them, and allows them to be completed electronically),

- management of patient data (stores patient history),

- analysis of collected data (e.g. to detect certain patterns or to propose diagnosis based on data collected about the patient),

- presentation of results to authorized users (e.g. results of analyzes can be shown graphically and presented to a doctor, patient, or authorized family members).

\section{The Future of Mobile Technologies in Diagnosing and Treating ADHD}

Nowadays, due to the fast pace of life, mobile IT solutions are characterized by growing approval and importance in everyday life. The widespread use of mobile devices (Rivera \& Goasduff, 2015), in particular smartphones, owing to their affordable price, and cheap access to wireless Internet are also significant. Gartner (Woods \& van der Meulen, 2016) predicted that by the end of $2016,82 \%$ of mobile phones would be smartphones. Due to the integration of many functions in one device, mobile devices are suitable for use in telemedicine and mobile medicine (the so-called m-Health). These devices are not only able to facilitate contact with patients, manage medical history and treatment (e.g. remind about the need for medication), but also to measure certain parameters of patients, useful in the diagnosis process. (Drigas et al., 2014; LoPresti et al., 2015; Silva et al., 2015)

Vital Wave Consulting (2009) distinguished the following areas of usefulness of $\mathrm{m}$-Health solutions:

- education and awareness raising,

- remote data collection,

- remote monitoring,

- communication and training of healthcare workers,

- tracking outbreaks/locations of disease occurrences.

Attempts are currently being made to implement mobile solutions in healthcare, but it is a lengthy process that requires formal approval. LoPresti et al. (2015) (based on the contents of the "clinicaltrials.gov" 
database) identified 50 attempts to study the role and usefulness of $\mathrm{m}$ Health in clinical settings, of which $88 \%$ were initiated in 2012-2014, and only $20 \%$ were completed. It was also noted that the main area of interest were chronic diseases, including neuropsychological ones.

Despite the great interest in using mobile technologies in the context of mental health (Henson et al., 2019; Luxton et al., 2011), there is still little valuable information on the results and challenges associated with their use. The same applies to the matter of mobile applications, for example Liu et al. (2011) selected 200 best m-Health mobile applications from Apple's App Store, of which only a small percentage was associated with monitoring and diagnosing a patient. What is more, Jusoh (2017) supports the position concerning the great impact of mobility on healthcare systems, highlighting in parallel the typical issues of m-Health applications, i.e. lack of a well-grounded theory and flaws in security and usability.

Lindhiem et al. (2015) presented a meta-analysis of the impact of the usage of mobile technologies in the field of psychotherapy. As part of literature review, the authors identified 26 publications describing 25 clinical trials using, among others, dedicated applications for smartphones and the ability to send text messages to support treatment, as well as to provide a substitute for direct contact with a doctor. According to Lindhiem et al. (2015), the use of mobile technologies is associated with achieving better results, which may constitute a recommendation for their use in psychotherapy.

Drigas et al. (2014) highlighted the benefits of using mobile technologies in the context of ADHD - as a way to maintain frequent contact with the patient and to manage and optimize the treatment process in situations of limited possibilities (e.g. resources or time) on the part of its participants. Kumar et al. (2013) and Zoe et al. (2014) present the concept and results of workshops aimed at identifying the needs and expectations of ADHD patients, their families and doctors regarding $\mathrm{m}$-Health applications. It turned out that doctors are particularly interested in receiving regular reports on the symptoms and effects of treatment, which also should be easily integrated with electronic patient records. In turn, providing functionality such as reminders of appointments or the necessity to take certain medications should increase the attractiveness of m-Health applications for patients and their families and friends. An attempt was also made to create an application that meets the identified expectations (Craven, 2014).

In addition, the following applications can be identified in the field of monitoring and supporting the treatment process: iRAM (Craven, 2014), WHAAM (Spachos et al., 2014), MedBuddy (Chen et al., 2012) and ADHD Angel (Anderton, 2019). In the field of ADHD detection/diagnosis (includ- 


\section{Kamil Żyła}

ing context-based diagnosis), AffectAura (McDuff et al., 2012) and Snappy App (Young et al., 2014) can be mentioned. In turn, as part of the treatment process, the Picaa platform (Fernandez-Lopez et al., 2013) and the Living SMART course (Moell et al., 2015) can be indicated - their therapeutic effects can be seen via: training the ability to focus attention and organize everyday life, or training skills, that are impaired by the existing disorders.

\section{Summary}

Present people cannot imagine a world detached from technology. It is present in more and more new fields, ranging from engineering, social sciences to m-Health applications utilizing advanced mobile devices. The goal of this paper was to discuss the use of technology, in particular modern computer-aided methods and mobile tools, in experimental ADHD diagnosis.

Considering the problem of ADHD from the psychological point of view, it has been noticed that an unambiguous diagnosis is difficult. The recognized symptoms may not necessarily be indicative of such a disorder. The main tests that those tested for ADHD are subjected to are all kinds of CPT tests, which might be accompanied by advanced devices (e.g. EEG, eye-tracker) for the acquisition of the person's parameters. Despite complex verification of data acquisition and diagnostic procedures, it is difficult to ensure accuracy, reliability, standardization, adaptation, and normalization of tests. Even seemingly mature methods, such as QEEG, give results against which researchers are divided (Ogrim et al., 2012).

It was noticed that classic methods (including CPT tests) are characterized by high accuracy and reliability of diagnosis. In contrast, mobile solutions are in the experimental phase, and the detection of a disorder is often based only on selected symptoms, i.e. they lack the desired comprehensiveness. Attempts are being made to implement m-Health applications in the field of disease monitoring and diagnosis (Henson et al., 2019; LoPresti et al., 2015). Legal aspects of the acquisition, retention and security of biomedical data related to this type of applications are also receiving more and more attention (Jusoh, 2017; Silva et al., 2015).

The growing role of computer-assisted methods in diagnosing ADHD can be noticed, but the equipment and software are not yet able to completely replace the diagnostician. Nevertheless, the natural direction of development seems to point at the construction of solutions for initial patient self-diagnosis and remote diagnosis, as well as constant improvement of al- 
ready established diagnostic methods and tools. Once a certain critical point is reached, a shift towards the standardization of storage, processing, and exchange of policy between applications and databases will occur.

\section{R E F E R E N C E S}

Adams, R., Finn, P., Moes, E., Flannery, K., \& Rizzo, A. S. (2009). Distractibility in Attention/Deficit/Hyperactivity Disorder (ADHD): the virtual reality classroom. Child Neuropsychology, 15(2), 120-135.

American Psychiatric Association (APA) (2013). Diagnostic and Statistical Manual of Mental Disorders, 5th edition. Arlington, VA: American Psychiatric Association.

American Psychiatric Association (APA) (2017). What is ADHD? Retrieved from https://www.psychiatry.org/patients-families/adhd/what-is-adhd

Anderton D. (2019). ADHD Angel. App Store Preview. Retrieved from https:// apps.apple.com/us/app/adhd-angel/id485821457

BIS Research (2018). Global mobile medical apps market to reach $\$ 11.22$ billion by 2025, reports BIS Research. CISION PR Newswire. Retrieved from https://www.prnewswire.com/news-releases/global-mobile-medical-apps-ma rket-to-reach-1122-billion-by-2025-reports-bis-research-674813873.html

Bresnahan, S. M., \& Barry, R. J. (2002). Specificity of quantitative EEG analysis in adults with attention deficit hyperactivity disorder. Psychiatry Research, 112(2), 133-144.

Chen, H., Yang, H., Hooks, H., Lee, J., Satterfield, D., Wong, J., \& Chang, C. K. (2012). Medbuddy: A mobile medicinal management system for children with ADD/ADHD. In Impact Analysis of Solutions for Chronic Disease Prevention and Management. Lecture Notes in Computer Science, 7251, 286-290. doi: 10.1007/978-3-642-30779-9_46

Cloud, J. (2011). The lab rat: A better way to diagnose ADHD. Time Health. Retrieved from http://healthland.time.com/2011/02/25/the-lab-rat-a-better -way-to-diagnose-adhd/

Conners, C. K. (2014). Conners CPT3: Continuous Performance Test 3rd edition. Multi-Health Systems Inc.

Craven M. P. (2014). Technologies for remote therapy and management-multiple criteria, multiple stakeholders. Symposium 6: Telemedicine, Royal College of Psychiatrists Faculty of Child and Adolescent Psychiatry Annual Residential Meeting (CAP2014). 17-19 September 2014. Cardiff. doi: 10.13140/RG.2.2.2 3704.90885

Díaz-Orueta, U., Garcia-López, C., Crespo-Eguílaz, N., Sánchez-Carpintero, R., Climent, G., \& Narbona, J. (2014). AULA virtual reality test as an attention measure: convergent validity with Conners' Continuous Performance Test. Child Neuropsychology, 20(3), 328-342. 


\section{Kamil Żyła}

Drigas, A. S., Ioannidou, R. E., Kokkalia, G., \& Lytras, M. D. (2014). ICTs, mobile learning and social media to enhance learning for attention difficulties. Journal of Universal Computer Science, 20(10), 1499-1510.

Epstein, J. N., \& Loren, R. E. A. (2013). Changes in the Definition of ADHD in DSM-5: Subtle but Important. Neuropsychiatry, 3(5), 455-458. doi: $10.2217 /$ npy. 13.59

European Commission (2018). Public consultation on the Green Paper on mobile health. Retrieved from https://ec.europa.eu/digital-single-market/en/public -consultation-green-paper-mobile-health

Fernandez-Lopez, A., Rodríguez-Fortiz, M. J., Rodríguez-Almendros, M. L., \& Martinez-Segura, M. J. (2013). Mobile learning technology based on iOS devices to support students with special education needs. Computers \& Education, 61, 77-90. doi: 10.1016/j.compedu.2012.09.014

Fried, M., Tsitsiashvili, E., Bonneh, Y. S., Sterkin, A., Wygnanski-Jaffe, T., Epstein, T., \& Polat, U. (2014). ADHD subjects fail to suppress eye blinks and microsaccades while anticipating visual stimuli but recover with medication. Vision Research, 101, 62-72.

Goasduff, L. (2019). Gartner says global smartphone sales continued to decline in second quarter of 2019. Gartner. Retrieved from https://www.gartner.com/ en/newsroom/press-releases/2019-08-27-gartner-says-global-smartphone-sal es-continued-to-dec

Gruessner, V. (2015). Remote monitoring tools offer comprehensive ADHD assessment. mHealth Intelligence. Retrieved from http://mhealthintelligence.com/ news/remote-monitoring-tools-offer-comprehensive-adhd-assessment

Hall, C. L., Valentine, A. Z., Groom, M. J., Walker, G. M., Sayal, K., Daley, D., \& Hollis, C. (2015). The clinical utility of the continuous performance test and objective measures of activity for diagnosing and monitoring ADHD in children: a systematic review. European Child 83 Adolescent Psychiatry, 25(7), 677-699. doi: 10.1007/s00787-015-0798-x

Henson, P., Peck, P., \& Torous, J. (2019). Considering the therapeutic alliance in digital mental health interventions. Harvard Review of Psychiatry, 27(4), 268-273. doi: 10.1097/HRP.0000000000000224

Jusoh, S. (2017). A survey on trend, opportunities and challenges of mHealth apps. International Journal of Interactive Mobile Technologies, 11(6), 73-85. doi: 10.3991/ijim.v11i6.7265

Kim, J., Lee, Y., Han, D., Min, K., Kim, D., \& Lee, C. (2015). The utility of quantitative electroencephalography and Integrated Visual and Auditory Continuous Performance Test as auxiliary tools for the Attention Deficit Hyperactivity Disorder diagnosis. Clinical Neurophysiology, 126(3), 532-540.

Kristensen, M., Kyng, M., \& Palen, L. (2006). Participatory design in emergency medical service: designing for future practice. In CHI '06 Proceedings of the SIGCHI Conference on Human Factors in Computing Sys- 
tems, 22-27 April 2006 (pp. 161-170). New York, NY, USA: ACM. doi: 10.1145/1124772.1124798

Kumar, S., Nilsen, W. J., Abernethy, A., Atienza, A., Patrick, K., Pavel, M., Riley, et al. (2013). Mobile health technology evaluation: the mHealth evidence workshop. American Journal of Preventive Medicine, 45(2), 228-236.

La Marca, J. P., Cruz, D., Fandino, J., Cacciaguerra, F. R., Fresco, J. J., \& Guerra, A. T. (2018). Evaluation of artifact-corrected electroencephalographic (EEG) training: a pilot study. Journal of Neural Transmission, 125(7), 1087-1097. doi: 10.1007/s00702-018-1877-1

Lindhiem, O., Bennett, C. B., Rosen, D., \& Silk, J. (2015). Mobile technology boosts the effectiveness of psychotherapy and behavioral interventionsa meta-analysis. Behavior Modification, 39(6), 785-804.

Liu, C., Zhu, Q., Holroyd, K. A., \& Seng, E. K. (2011). Status and trends of mobilehealth applications for iOS devices: a developer's perspective. Journal of Systems and Software, 84(11), 2022-2033.

LoPresti, M. A., Abraham, M. E., Appelboom, G., Bruyère, O., Slomian, J., Reginster, J. Y., \& Connolly, Jr. E. S. (2015). Clinical trials using mobile health applications. Pharmaceutical Medicine, 29(1), 17-25.

Luxton, D. D., McCann, R. A., Bush, N. E., Mishkind, M. C., \& Reger, G. M. (2011). mHealth for mental health: integrating smartphone technology in behavioral healthcare. Professional Psychology: Research and Practice, 42(6), $505-512$.

Markovska-Simoska, S., \& Pop-Jordanova, N. (2011). Quantitative EEG spectrumweighted frequency (brain rate) distribution in adults with ADHD. CNS Spectrums, 16(5), 111-119.

McDuff, D., Karlson, A., Kapoor, A., Roseway, A., \& Czerwinski, M. (2012). AffectAura: an intelligent system for emotional memory. In Proceeding of the SIGCHI Conference on Human Factors in Computing Systems, 5-10 May 2012 (pp. 849-858). Texas, USA: ACM. doi: 10.1145/2207676.2208525

Moell, B., Kollberg, L., Nasri, B., Lindefors, N., \& Kaldo, V. (2015). Living SMART- a randomized controlled trial of a guided online course teaching adults with ADHD or sub-clinical ADHD to use smartphones to structure their everyday life. Internet Interventions, 2, 24-31.

Monastra, V. J., \& Lubar, J. F. (2000). Quantitative electroencephalographic (QEEG) process and apparatus for assessing attention deficit hyperactivity disorder. United States Patent US006097980A.

Namahoot, C. S., \& Brückner, M. (2015). SPEARS: Smart phone emergency and accident reporting system using social network service and Dijkstra's algorithm on Android. Lecture Notes in Electrical Engineering, 310, 173-182.

Nolin, P., Stipanicic, A., Henry, M., Lachapelle, Y., Lussier-Desrochers, D., Rizzo, A. "Skip", \& Allain, P. (2016). ClinicaVR: Classroom-CPT: A virtual reality tool for assessing attention and inhibition in children and adolescents. Computers in Human Behavior, 59, 327-333. doi: 10.1016/j.chb.2016.02.023 


\section{Kamil Żyła}

Ogrim, G., Kropotov, J., \& Hestad, K. (2012). The QEEG theta/beta ratio in ADHD and normal controls: sensitivity, specificity, and behavioral correlates. Psychiatry Research, 198(3), 482-488.

Optimal Medicine (2019a). Introducing a major breakthrough-software for assessing and treating your patients with ADHD. Retrieved from http://www.me health.com

Optimal Medicine (2019b). Quick guide to mehealth for ADHD. Retrieved from https://vimeo.com/127723405

Orbis Research (2017). mHealth market worth $\$ 23$ billion in 2017 and estimated to grow at a CAGR of more than $35 \%$ over the next three years. Reuters Plus. Retrieved from https://www.reuters.com/brandfeatures/venture-capital/ar ticle?id $=4640$

Paloyelis, Y., Mehta, M. A., Kuntsi, J., \& Asherson, P. (2007). Functional MRI in ADHD: a systematic literature review. Expert Review of Neurotherapeutics, 7(10), 1337-1356.

Parsons, T. D., Bowerly, T., Buckwalter, J. G., \& Rizzo, A. A. (2007). A controlled clinical comparison of attention performance in children with ADHD in a virtual reality classroom compared to standard neuropsychological methods. Child Neuropsychology, 13(4), 363-381.

Pearson (2019). Quotient ADHD System. Retrieved from https://www.pearson assessments.com/store/usassessments/en/Store/Professional-Assessments/ Behavior/Attention-ADHD/Quotient-ADHD-Test/p/100000942.html

Pędziński, B., Sowa, P., Pędziński, W., Krzyżak, M., Maślach, D., \& Szpak, A. (2013). Information and communication technologies in primary healthcare - barriers and facilitators in the implementation process. Studies in Logic, Grammar and Rhetoric, 35(48), 179-189.

Pollak, Y., Weiss, P. L., Rizzo, A. A., Weizer, M., Shriki, L., Shalev, R. S., \& GrossTsur, V. (2009). The utility of a Continuous Performance Test embedded in virtual reality in measuring ADHD-related deficits. Journal of Developmental \& Behavioral Pediatrics, 30(1), 2-6.

Puig, M. S., Zapata, L. P., Aznar-Casanova, J. A., \& Supèr, H. (2013). A role of eye vergence in covert attention. PLoS One, 8(1), 1-10. doi: 10.1371/ journal.pone.0052955

Rivera, J., \& Goasduff, L. (2015). Gartner says smartphone sales surpassed one billion units in 2014. Gartner. Retrieved from https://www.gartner.com/en/ newsroom/press-releases/2015-03-03-gartner-says-smartphone-sales-surpass ed-one-billion-units-in-2014

Rizzo, A. A., Bowerly, T., Shahabi, C., Buckwalter, J. G., Klimchuk, D., \& Mitura, R. (2004). Diagnosing attention disorders in a virtual classroom. Computer, $37(6), 87-89$. 
Rohani, D. A., Sorensen, H. B. D., \& Puthusserypady, S. (2014). Brain-computer interface using P300 and virtual reality: a gaming approach for treating ADHD. In Proceedings of 36th Annual International Conference of the IEEE Engineering in Medicine and Biology Society, 26-30 August 2014, Chicago, IL (pp. 3606-3609). IEEE.

Rojas-Líbano, D., Wainstein, G., Carrasco, X., Aboitiz, F., Crossley, N., \& Ossandón, T. (2019). A pupil size, eye-tracking and neuropsychological dataset from ADHD children during a cognitive task. Scientific Data, 6, 1-6. doi: 10.1038/s41597-019-0037-2

Rotem, A., Danieli, Y., Ben-Sheetrit, J., Bashari, A., Golubchik, P., Ben-Hayun, R., Weizman, A., et al. (2019). Apparent lack of practice effects in the Test of Variables of Attention (TOVA) in adult ADHD. ADHD Attention Deficit and Hyperactivity Disorders, 11(1), 73-81. doi: 10.1007/s12402-018-0278-5

Ryan, P. (2017). VR v. ADHD: A future solution for millions worldwide. VR Fitness Insider. Retrieved from https://www.vrfitnessinsider.com/vr-adhd/

Saul, R. (2014). ADHD does not exist: The truth about Attention Deficit and Hyperactivity Disorder. Harper Wave.

Schneider, H., Thornton, J. F., Freeman, M. A., McLean, M. K., van Lierop, M. J., \& Schneider, J. (2014). Conventional SPECT versus 3D thresholded SPECT imaging in the diagnosis of ADHD: a retrospective study. The Journal of Neuropsychiatry and Clinical Neurosciences, 26(4), 335-343.

Silva, B. M. C., Rodrigues, J. J. P. C., de la Torre Diez, I., López-Coronado, M., \& Saleem, K. (2015). Mobile-health: a review of current state in 2015. Journal of Biomedical Informatics, 56, 265-272.

Smith, M. (2017). Hyperactive around the world? The history of ADHD in global perspective. Social History of Medicine, 30(4), 767-787. doi: 10.1093/shm/ hkw127

Spachos, D., Chifari, A., Chiazzese, G., Merlo, G., Doherty, G., \& Bamidis, P. (2014). WHAAM: a mobile application for ubiquitous monitoring of ADHD behaviors. In Proceedings of International Conference on Interactive Mobile Communication Technologies and Learning, Thessaloniki, 13-14 November 2014 (pp. 305-309). IEEE.

Steinau, S. (2013). Diagnostic criteria in Attention Deficit Hyperactivity Disorder Changes in DSM 5. Frontiers in Psychiatry, 4. doi:10.3389/fpsyt.2013.00049

Taylor, H. (2015). How mobile will transform business in 2016: Forrester. CNBC. Retrieved from http://www.cnbc.com/2015/11/09/forrester-mobile-predicti ons-for-2016.html

The Virtual Reality Medical Center (VRMC) (2019, August 30). Retrieved from https://vrphobia.com

Tinius, T. P. (2003). The Integrated Visual and Auditory Continuous Performance Test as a neuropsychological measure. Archives of Clinical Neuropsychology, 18(5), 439-454. doi: 10.1016/S0887-6177(02)00144-0 


\section{Kamil Żyła}

Vital Wave Consulting (2009). mHealth for development: the opportunity of mobile technology for healthcare in the developing world. United Nations Foundation-Vodafone Foundation Partnership.

Weyandt, L., Swentosky, A., \& Gudmundsdottir, B. G. (2013). Neuroimaging and ADHD: fMRI, PET, DTI findings, and methodological limitations. Developmental Neuropsychology, 38(4), 211-225.

Woods, V., \& van der Meulen, R. (2016). Worldwide device shipments to grow 1.9 percent in 2016, while end-user spending to decline for the first time. Gartner. Retrieved from http://www.gartner.com/newsroom/id/3187134

Yeh, S., Tsai, C., Fan, Y., Liu, P., \& Rizzo, A. (2012). An innovative ADHD assessment system using virtual reality. In Proceedings of IEEE-EMBS Conference on Biomedical Engineering and Sciences, Langkawi, 17-19 December 2012 (pp. 78-83). IEEE.

Young, Z., Craven, M. P., Groom, M., \& Crowe, J. (2014). Snappy App: a mobile Continuous Performance Test with physical activity measurement for assessing attention deficit hyperactivity disorder. In Human-Computer Interaction. Applications and Services. Lecture Notes in Computer Science, 8512, 363-373. doi: 10.1007/978-3-319-07227-2_35

Ziniewicz, P., Malinowski, P., Milewski, R., Mnich, Z. S., \& Wołczyński S. (2011). Clinical department information system's internal structure. Studies in Logic, Grammar and Rhetoric, 25(38), 191-200.

Zoe, Y., Simons, L., Craven, M., Groom, M., \& Hollis, C. (2014). Remote monitoring of Attention-Deficit Hyperactivity Disorder (ADHD) symptoms using mobile phone technology. International Journal of Integrated Care, 14, 189-190. 